\title{
Changes in health-related quality of life before and after a 12-month enhanced primary care model among chronically ill primary care patients in Australia
}

\author{
James Rufus John ${ }^{1,2^{*}}$ (D, W. Kathy Tannous ${ }^{1,3}$ and Amanda Jones ${ }^{4}$
}

\begin{abstract}
Purpose: Evidence suggests that Patient-centred Medical Home (PCMH) model facilitates person-centred care and improves health-related quality of life for patients with chronic illness. This study aims to evaluate changes in health-related quality of life (HRQOL), before and after enrolment into a 12-month integrated care program called 'WellNet'.

Methods: This study includes 616 eligible consented patients aged 40 years and above with one or more chronic conditions from six general practices across Sydney, Australia. The WellNet program included a team of general practitioners (GPs) and clinical coordinators (CCs) providing patient-tailored care plans configured to individual risk and complexity. HRQoL was recorded using the validated EuroQol five dimensions five levels (EQ-5D-5L) instrument at baseline and 12 months. Additionally, patients diagnosed with osteoarthritis also reported HRQoL using short versions of Knee and/or Hip disability and osteoarthritis outcome scores (KOOSjr and HOOSjr). A case-series study design with repeated measures analysis of covariance (ANCOVA) was used to assess changes in mean differences of EQ-5D index scores after controlling for baseline covariates. Additionally, backward stepwise multivariable linear regression models were conducted to determine significant predictors of EQ-5D index scores at follow-up.

Results: Out of 616 patients, 417 (68\%) reported EQ-5D scores at follow-up. Almost half (48\%) of the WellNet patients reported improved EQ-5D index scores at follow-up. After controlling for baseline covariates, the adjusted mean difference was statistically significant whilst also meeting the bare minimal clinically important difference (MCID) with a change of 0.03 (95\% Cl 0.01, 0.05). The multivariable regression models determined that baseline EQ5D scores and positive diagnosis of a respiratory illness were significant predictors of HRQoL at follow-up. There were significant improvements across both KOOS and HOOS assessments, specifically, the pain and symptom scores in both scales met statistical significance in addition to meeting the MCID.

(Continued on next page)
\end{abstract}

\footnotetext{
* Correspondence: 18314234@student.westernsydney.edu.au

${ }^{1}$ Translational Health Research Institute, Western Sydney University, Campbelltown, Sydney, NSW 2560, Australia

${ }^{2}$ Rozetta Institute (formerly Capital Markets Cooperative Research Centre),

The Rocks, Sydney, NSW 2000, Australia

Full list of author information is available at the end of the article
}

C C The Author(s). 2020 Open Access This article is licensed under a Creative Commons Attribution 4.0 International License, which permits use, sharing, adaptation, distribution and reproduction in any medium or format, as long as you give appropriate credit to the original author(s) and the source, provide a link to the Creative Commons licence, and indicate if changes were made. The images or other third party material in this article are included in the article's Creative Commons licence, unless indicated otherwise in a credit line to the material. If material is not included in the article's Creative Commons licence and your intended use is not permitted by statutory regulation or exceeds the permitted use, you will need to obtain permission directly from the copyright holder. To view a copy of this licence, visit http://creativecommons.org/licenses/by/4.0/. The Creative Commons Public Domain Dedication waiver (http://creativecommons.org/publicdomain/zero/1.0/) applies to the data made available in this article, unless otherwise stated in a credit line to the data. 
(Continued from previous page)

Conclusion: Patient-tailored chronic disease management (CDM) plans designed by team of GPS and CDM clinical coordinators could lead to better HRQoL among primary care patients.

Keywords: Quality of life, EuroQol (EQ-5D), Multimorbidity, Chronic disease, Integrated care, Collaborative care, Chronic care model, Australia

\section{Introduction}

The exponential rise in chronic disease prevalence presents significant public health burden to health care systems worldwide and challenges the need to revisit strategies towards effective prevention and management $[1,2]$. In Australia, chronic conditions have accounted for $87 \%$ of deaths and a collective $61 \%$ of fatal and nonfatal burden in $2015[3,4]$. Moreover, there is an increasing trend of multimorbidity among the ageing population resulting in greater demand for integration of health services $[5,6]$. The health and economic ramifications of chronic illness in terms of premature mortality [7], polypharmacy [8], complexity of care [9], and diminished health-related quality of life [10] are well documented. Additionally, the increased health service utilisation among chronic disease sufferers is especially of interest, given Australia's current fragmented health care framework which lacks continuity of care and care coordination $[11,12]$. On the contrary, there is increasing evidence of improved health-related quality of life (HRQoL) in patients receiving collaborative and patientcentred care $[13,14]$.

In recent decades, there has been a paradigm shift in the measure of health care evaluation from the traditional health indicators of mortality and morbidity towards a broader perspective of patient reported outcome measures (PROMS) including daily functioning, quality of life, symptoms, and other aspects of their health [15, 16]. HRQoL is a multi-dimensional concept that measures the impact and quality of health encompassing an individual's physical, mental, and social functioning [17, 18]. Determining the HRQoL for patients with chronic illness in primary care setting is beneficial as it enables understanding of patient's insights and perception on where care needs to be directed in relation to their condition $[19,20]$. This in turn allows providers to improve self-management behaviours among patients to effectively manage their conditions and symptoms [21]. There is evidence showing strong association between patientprovider communication and improved HRQoL [22, 23].

Australia has a long-standing use of surveys to measure population health quality and status, including recent incorporation of health utility measures. Data from the South Australia's annual Health Omnibus Survey (HOS) and New South Wales' 45 and Up Study have been extensively used to study HRQoL in several widelevel population norms $[24,25]$. For instance, trends in the HRQoL study by Atlantis et al. shows that HRQoL significantly worsened over a 10-year period (19982008) for individuals with comorbid conditions compared to those with a single chronic condition [26]. Despite recent work, current knowledge of the HRQoL among specific population groups, like primary care patients with one or more chronic conditions, remains largely unknown. Therefore, the aim of this study is to evaluate the HRQoL, before and one-year after enrolment into an enhanced primary care program, and to investigate predictors of change in the HRQoL among primary care patients presenting with one or more chronic conditions.

\section{Methods}

\section{WellNet program - overview, intervention, and study} design

The 'WellNet' program developed by Sonic Clinical Services (SCS) is a general practitioner (GP) led, multidisciplinary team-based (MDT) care delivery model within primary care settings. The 12-month program is built upon best practice clinical care models, including the Patient-Centred Medical Home (PCMH), which aims to deliver care that is tailored to individual risk and comorbidity burden [27].

The enhanced primary care program is designed to provide individualised 'whole-person' care with focus on self-management support, health coaching and education, care coordination, shared decision making, and long-term continuity of care. Ongoing support and monitoring were provided through a total of 14 possible consultations with the care team in the form of in-practice visits and telephone contacts throughout the 12-month period. In addition, patients were also supported with a user-friendly online platform called 'GoShare' providing patient-tailored educational materials and a mobile application 'MediTracker' enabling access and reminders to the next scheduled GP appointments and prescriptions. Further details on how CCs monitored usage of GoShare and MediTracker are reported elsewhere [27].

Patients were recruited between December 2016 and October 2017 using a targeted convenience sampling technique if they met the eligibility criteria. Targeted 
convenience sampling is a commonly used nonprobability sampling in clinical research where members of the target population that meet certain practical eligibility criteria are included for the purpose of the study [28]. A case-series study design was used to determine changes in the HRQoL before and after WellNet care among patients enrolled in six primary care practices across Northern Sydney, Australia. Informed consent was obtained from all participants upon enrolment into the WellNet program.

\section{Participants}

A computerised algorithm was executed to identify potentially eligible patients from the electronic medical records of SCS GP practices. The overarching criteria for eligibility include patients aged 40 years and over; having one or more chronic condition/s with or without one or more elevated clinical risk factors; and had visited a GP at least thrice in the previous 2 years. Patients living in nursing homes and those with severe cognitive impairment or terminal illness $(n=10)$ were excluded. More details on the risk algorithm, enrolment, and data collection are reported elsewhere [27]. Of the 636 consenting participants, 616 who completed the EuroQol five dimensions and five levels version (EQ-5D-5L) questionnaire at baseline were analysed in this study. Flowchart of the enrolment outcomes is shown in Fig. 1.

\section{EQ-5D-5L instrument}

The HRQoL was measured using the standardised UK version of the EQ-5D-5L instrument [29]. The questionnaire covers five dimensions of health: mobility, selfcare, usual activities, pain or discomfort, and anxiety or depression. The levels of severity range from no problems (1) to extreme problems (5) for each of the five dimensions are recorded. The raw scores are then converted to a single EQ-5D index value using a scoring algorithm ranging from 0 (worst perceived health state) to 1 (best perceived health state) [30]. In this study, the UK version of scoring algorithm and value set were employed to calculate utility scores as an Australian scoring algorithm is unavailable for the $5 \mathrm{~L}$ version. The

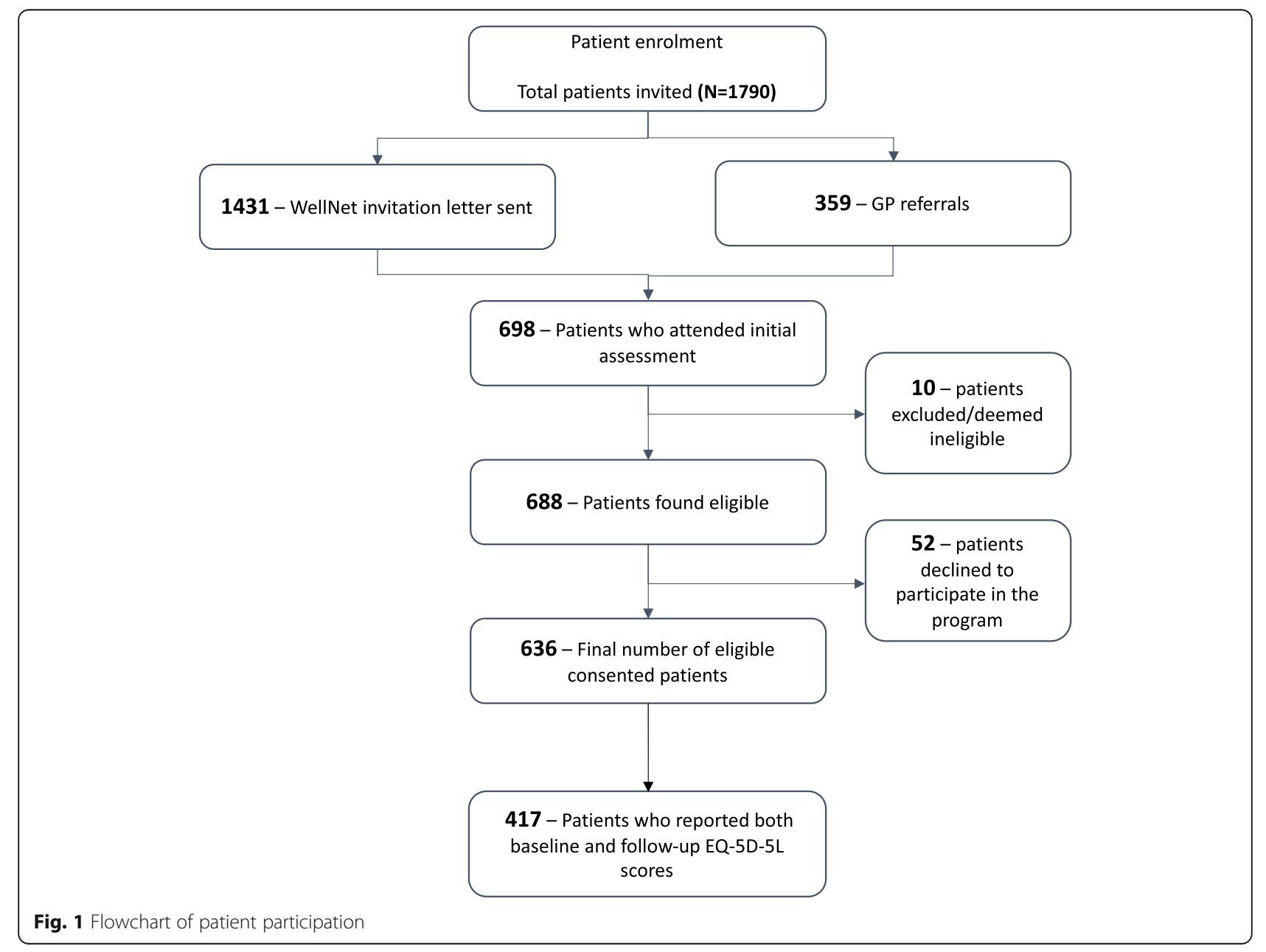


UK algorithm was estimated using a hybrid model of preference data collected using a time-trade off and discrete choice experiment methods $[29,30]$ and potential values from this algorithm ranged from -0.281 to 1 , where values lower than 0 represent states considered to be worse than death [29].

In the WellNet program, EQ-5D-5L questionnaire was recorded at baseline and 12 months (at program completion). For studies measuring the impact of treatment outcome/s, the minimal clinically important difference (MCID) reports on the smallest change in the outcome of interest that is considered to be clinically significant or meaningful [31]. A comprehensive review of 18 studies by Coretti et al. [32] estimated the overall MCID for EQ-5D-5L range to be, for musculoskeletal disorders, between 0.03 and 0.54 .

\section{KOOS and HOOS assessments (short versions)}

The Hip disability and Osteoarthritis Outcome Scores (HOOS) and Knee injury and Osteoarthritis Outcome Scores (KOOS) are shortened but validated versions of the HOOS and KOOS surveys indicated for patients with a positive diagnosis of osteoarthritis and reporting different forms of hip and knee disability $[33,34]$. These surveys are intended for use over short and long-term intervals to assess patientreported changes in the quality of life in terms of changes in the levels of function, symptoms, and pain induced by a particular treatment [33, 34].

Both the questionnaires contain subscales of items recording patient's QoL in terms of pain, function, daily living, and stiffness. The raw scores for each subscale range from 0 to 24 which are then converted to interval scores using online calculators made available on the Ortho Tool kit website [35]. The interval scores range from 0 to 100: 0 indicates total disability, whilst 100 indicates perfect functionality. As MCIDs were not established at the start of this study, previous body of literature estimations were adopted where MCID values ranging between 9.6 and 16.2 for HOOS; and between 8 and 10 for KOOS [36, 37]. In this study, the HOOS and KOOS scales were only used as a supplement to EQ-5D instrument.

\section{Study outcomes and exploratory variables}

The primary outcome of interest was changes in the EQ-5D index value and increase in the proportion of patients at 'no problem' level in all five dimensions at follow-up. The secondary outcomes included: 1) predictors of change in EQ-5D index over time; 2) adjusted mean difference in KOOS and HOOS scales recorded among subsample of patients diagnosed with osteoarthritis.
The explanatory or predictor variables analysed and adjusted for in this study as follows: age, gender, diagnosis of chronic conditions, number of co-existing conditions, private health insurance status (PHI), and number of scheduled consultations.

The changes in the levels of each dimension from baseline to follow-up were classified as follows: - - no problem level to no problem level (no change); - + lower problem level to a higher problem level (impairment); + - higher problem level to a lower problem level (improvement); ++ higher problem to higher problem (no change).

\section{Data analysis}

Descriptive statistics for continuous variables are expressed as mean and standard deviation (SD) whereas frequency counts of categorical variables are shown in percentages. Normality of distribution was assessed using the Shapiro-Wilk test for normality and by analysis of normal quantile-quantile plots. Independent samples t-tests and Pearson's chi-square tests were conducted to determine significant differences between completers and those who withdrew (non-completers) before program completion. Additionally, Pearson's product-moment correlation coefficient was conducted to determine the level of association between EQ. 5D scores and different chronic condition groups at baseline.

Unadjusted mean differences between baseline and follow-up were computed using paired samples t-test. The adjusted mean differences were determined by using the repeated measures analysis of covariance (ANCOVA) whilst adjusting for potential baseline covariates such as age, gender, diagnosis of chronic conditions, number of co-existing conditions, PHI status, and number of scheduled consultations. Additionally, subgroup analyses were also conducted to evaluate adjusted differences in EQ. 5D scores between proportion of patients based on number of chronic conditions (one and two or more conditions) and median contacts ( $<12$ contacts and $\geq 12$ contacts) with WellNet care team.

To determine predictors of change in EQ-5D over time, multivariable linear regression models were employed using post-EQ. 5D index scores as outcome variable. Post-EQ. 5D index scores were preferred over change scores (follow-up minus baseline) as outcome variable because change scores fail to allow for optimal control of the baseline imbalance owing to potential regression to the mean [38, 39]. Univariate linear regression was conducted for each variable separately and variables with $p$-value $<0.20$ were included in the multivariable model. The backward stepwise regression approach was used to reduce and create the 
final model while simultaneously assessing the fitness of model in order to avoid dropping of nonsignificant variables that may affect the model fitness. The final model constitutes variables, which when excluded, cause a prominent deviance change $(p<0.05)$ as compared to the corresponding $\mathrm{X}^{2}$ test statistic on the relevant degrees of freedom.

Finally, the internal consistency of EQ-5D, KOOS, and HOOS scales in this study were evaluated using Cronbach's alpha. All analyses were conducted using SPSS (version 25) and R statistical software.

\section{Results}

Baseline characteristics and EQ-5D-5L scores

Baseline characteristics of patients including chronic disease prevalence, overall and stratified by completion status, are presented in Table 1. With exception to slight differences in proportions of those diagnosed with musculoskeletal disorder, no significant differences were observed between those who completed baseline and follow-up assessments and those completing baseline assessment only in terms of sociodemographic characteristics or clinical measures. Patients were on average 68.9

Table 1 Baseline patient characteristics (Overall, by completion status)

\begin{tabular}{|c|c|c|c|c|}
\hline Variable & Overall $(\boldsymbol{N}=616)$ & $\begin{array}{l}\text { Baseline and follow-up } \\
\text { assessments }(\boldsymbol{n}=417)\end{array}$ & $\begin{array}{l}\text { Baseline assessment } \\
\text { only }(\boldsymbol{n}=199)\end{array}$ & $\boldsymbol{p}$-value \\
\hline Age in years, Mean (SD) & $68.9(12.9)$ & $69.6(12.1)$ & $67.4(14.2)$ & 0.063 \\
\hline \multicolumn{5}{|l|}{ Gender } \\
\hline Males & $306(49.7)$ & $200(48.0)$ & $106(53.3)$ & \multirow[t]{2}{*}{0.218} \\
\hline Females & $310(50.3)$ & $217(52.0)$ & $93(46.7)$ & \\
\hline \multicolumn{5}{|l|}{ History of co-existing conditions } \\
\hline Cardiovascular disease & $211(34.3)$ & $147(35.3)$ & $64(32.2)$ & 0.450 \\
\hline Respiratory disease & $179(29.1)$ & $119(28.5)$ & $60(30.2)$ & 0.680 \\
\hline Diabetes & $302(49.0)$ & $213(51.1)$ & 89 (44.7) & 0.140 \\
\hline Musculoskeletal disorders & $263(42.7)$ & $191(45.8)$ & $72(36.2)$ & 0.024 \\
\hline Mental illness & $126(20.5)$ & $81(19.4)$ & $45(22.6)$ & 0.359 \\
\hline Cancer & $89(14.4)$ & $57(13.7)$ & $32(16.1)$ & 0.426 \\
\hline Number of co-existing conditions, Mean (SD) & $1.9(0.9)$ & $1.9(1.0)$ & $1.8(0.9)$ & 0.150 \\
\hline \multicolumn{5}{|l|}{ Chronic conditions } \\
\hline One condition & $219(35.6)$ & $141(33.8)$ & $78(39.2)$ & \multirow[t]{2}{*}{0.192} \\
\hline Two or more conditions & $397(64.4)$ & $276(66.2)$ & $121(60.8)$ & \\
\hline \multicolumn{5}{|l|}{ Program contacts } \\
\hline$<12$ contacts & $313(50.8)$ & $130(31.2)$ & $183(92.0)$ & \multirow[t]{2}{*}{$<0.001$} \\
\hline$\geq 12$ contacts & $303(49.2)$ & $287(68.8)$ & $16(8.0)$ & \\
\hline \multicolumn{5}{|l|}{ Insurance status } \\
\hline Private & $391(68.5)$ & $268(68.9)$ & $123(67.6)$ & \multirow[t]{2}{*}{0.753} \\
\hline Uninsured & $180(31.5)$ & $121(31.1)$ & $59(32.4)$ & \\
\hline Mean EQ-5D-5L score & $0.79(0.19)$ & $0.79(0.18)$ & $0.78(0.21)$ & 0.493 \\
\hline \multicolumn{5}{|l|}{ Clinical measures } \\
\hline Systolic Blood Pressure (mmHg), Mean (SD) & $138.8(19.2)$ & $138.9(18.6)$ & $138.3(20.3)$ & 0.696 \\
\hline Diastolic Blood Pressure (mmHg), Mean (SD) & $75.8(18.0)$ & $76.2(17.1)$ & $75.1(19.9)$ & 0.500 \\
\hline Body Mass Index Kg/m2, Mean (SD) & $29.9(7.3)$ & $29.6(6.4)$ & $30.5(8.7)$ & 0.146 \\
\hline Glycated Haemoglobin (\%), Mean (SD) & $6.8(1.4)$ & $6.8(1.5)$ & $6.7(1.3)$ & 0.380 \\
\hline High Density Lipoprotein Cholesterol (mmol/L), Mean (SD) & $1.3(0.4)$ & $1.3(0.4)$ & $1.3(0.4)$ & 0.695 \\
\hline Low Density Lipoprotein Cholesterol (mmol/L), Mean (SD) & $2.7(1.1)$ & $2.7(1.0)$ & $2.9(1.1)$ & 0.059 \\
\hline Total Cholesterol (mmol/L), Mean (SD) & $4.8(1.4)$ & $4.8(1.3)$ & $4.9(1.5)$ & 0.105 \\
\hline Triglyceride (mmol/L), Mean (SD) & $1.7(1.1)$ & $1.6(1.1)$ & $1.7(1.2)$ & 0.352 \\
\hline
\end{tabular}

Data presented as $\mathrm{N}$ (\%) unless specified otherwise

Variables reported as percentages were tested with chi-square analyses and variables reported as means and standard deviations were tested with independent samples t-test

Bold letters suggest statistical significance with $p$-value $<0.05$ 
years old with almost similar gender distribution and had a mean number of $2 \pm 1$ chronic conditions. Diabetes (49\%) was observed to be the most prevalent of the chronic conditions with cancer (14\%) being the least prevalent among the WellNet patients. Additionally, more than two-thirds $(69 \%)$ of the participating patients had private insurance.

The overall mean (SD) EQ-5D index value of the sample at baseline was $0.79(0.19)$. Of the 616 patients who reported their baseline EQ-5D scores, 91 (15\%) patients reported 'no problems' across all five dimensions at baseline. 417 out 616 (68\%) participants reported followup EQ-5D upon program completion. In terms of the type of chronic condition, people diagnosed with a mental illness reported the least mean (SD) EQ-5D index value of $0.70(0.23)$ at baseline. Additionally, results of Pearson's product-moment correlation coefficient (unadjusted) showed a small but statistically significant negative association between baseline EQ-5D index value and history of a mental illness $(r=-0.24$, $p<0.001)$ and musculoskeletal disorder $(r=-0.21$, $p<0.001)$ at baseline. The distribution of baseline EQ$5 \mathrm{D}$ index value by type of chronic conditions with Pearson's correlation coefficients are presented in Fig. 2.

The internal consistency of EQ-5D items in this study was sound (Cronbach's alpha coefficients $=0.85$ ). Additionally, HOOS and KOOS items also showed high reliability with Cronbach's alpha coefficients of 0.91 and 0.89 respectively.

\section{Changes in the EQ-5D-5L scores}

The unadjusted within-group changes in the index value scores between baseline and follow-up showed statistically significant improvement with mean difference of 0.03 (95\% CI 0.02, 0.05). After controlling for baseline covariates, the adjusted mean difference remained significant with $0.03(95 \%$ CI $0.01,0.05)$ (Table 2).

Additionally, the subgroup analysis based on number of chronic conditions showed that patients with two or more chronic conditions $(N=276)$ observed higher adjusted mean difference in EQ. 5D scores of 0.04 (95\% CI 0.02 to $0.06 ; p$-value $<0.05)$ compared to patients with one chronic condition with adjusted mean difference of $0.01(95 \%$ CI -0.01 to $0.03 ; p$-value $=0.258)$. However, patients who had 12 or more contacts $(N=287)$ with the care team had similar improvements in EQ. 5D scores as those with less than 12 contacts $(N=130)$ with adjusted mean differences of 0.03 (95\% CI 0.00 to 0.04 ; $p$-value $<0.05$ ) (Table 2).

In terms of the changes in the levels of each dimension from baseline to follow-up, the proportion of patients showing improvement from higher to lower problem level was higher in all dimensions compared to the proportion reporting impairment from lower to higher problem level at follow-up (Table 3).

\section{Predictors of change in EQ-5D-5L scores over 12 months}

Findings of the multivariable linear regression analyses showing significant predictors of EQ-5D scores at 12 months are presented in Table 4. Higher baseline EQ5D-5L score was significantly positively associated with follow-up EQ-5D-5L scores ( $B=0.60 ; 95 \%$ CI 0.52 to 0.67 at $p<0.001)$. In addition, a positive diagnosis of respiratory disease was significantly negatively associated with EQ-5D-5L scores at 12 months compared to those

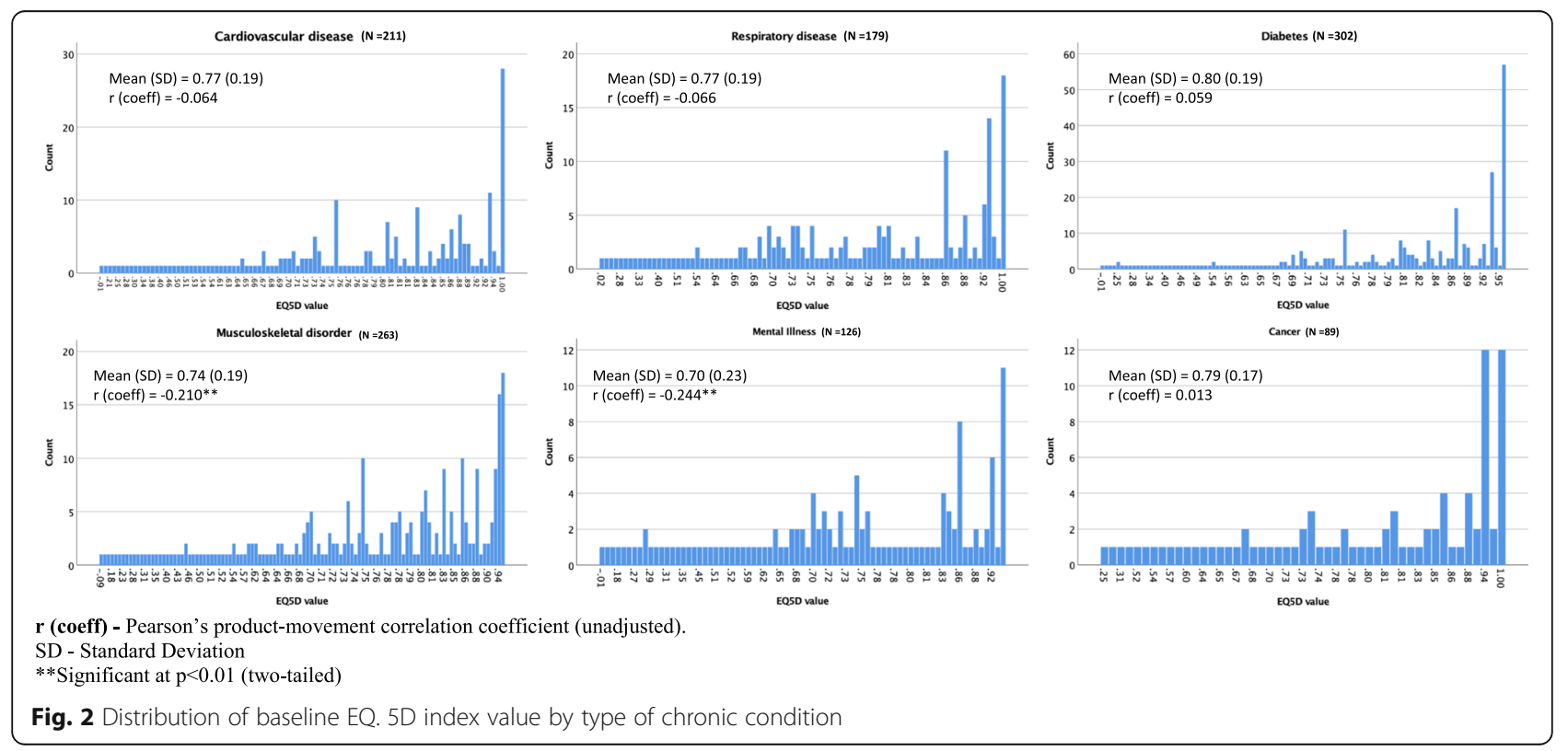


Table 2 Repeated measures ANCOVA with overall and subgroup analyses

\begin{tabular}{|c|c|c|}
\hline \multirow[t]{2}{*}{ Variable } & \multicolumn{2}{|l|}{ Complete cases analysis $(\boldsymbol{N}=417)$} \\
\hline & Unadjusted mean difference $(95 \% \mathrm{Cl})$ & Adjusted mean difference $(95 \% \mathrm{Cl})^{\mathbf{a}}$ \\
\hline Overall & $0.03(0.02,0.05)^{* *}$ & $0.03(0.01,0.05)^{* *}$ \\
\hline \multicolumn{3}{|l|}{ Subgroup analyses } \\
\hline \multicolumn{3}{|l|}{ Number of chronic conditions } \\
\hline One chronic condition $(n=141)$ & $0.01(0.00,0.03)$ & $0.01(-0.01,0.03)$ \\
\hline Two or more chronic conditions $(n=276)$ & $0.04(0.02,0.06)^{* *}$ & $0.04(0.02,0.06)^{*}$ \\
\hline \multicolumn{3}{|l|}{ Median program contacts } \\
\hline$<12$ contacts $(n=130)$ & $0.03(0.01,0.06)^{*}$ & $0.03(0.01,0.07)^{*}$ \\
\hline$\geq 12$ contacts $(n=287)$ & $0.03(0.01,0.05)^{* *}$ & $0.03(0.00,0.04)^{*}$ \\
\hline
\end{tabular}

${ }^{\mathrm{a}}$ Adjusted for age, gender, diagnosis of chronic conditions, number of co-existing conditions, private insurance status (PHI), and number of scheduled consultations

** $p$-value $<0.001$

${ }^{*} p$-value $<0.05$

without respiratory disease $(B=-0.03 ; 85 \% \mathrm{CI}-0.06$ to -0.01 at $p=0.034)$. The number of chronic conditions was not significant at the final model.

\section{Changes in KOOS and HOOS assessment at follow-up}

Of the 97 patients with diagnosis of osteoarthritis, 55 reported KOOS outcomes and 30 reported HOOS outcomes at baseline and follow-up. There were significant improvements across all subscales of both the KOOS and HOOS assessments. Specifically, the pain and symptom scores in both scales met statistical significance in addition to meeting the MCID (Table 5). 24 out of 55 (44\%) patients had adjusted mean differences met the MCID threshold for KOOS whereas 15

Table 3 Changes in the levels of EQ. 5D by dimension between baseline and follow-up

\begin{tabular}{|c|c|c|c|}
\hline EQ 5D dimensions & $\begin{array}{l}\text { Change in the levels between } \\
\text { baseline and follow-up }\end{array}$ & N (\%) & $\boldsymbol{p}$-value* \\
\hline \multirow[t]{4}{*}{ Mobility } & No change $(--)$ & 158 (37.9) & $<0.001$ \\
\hline & Impairment $(-+)$ & 75 (18.0) & \\
\hline & Improvement (+ -) & $101(24.2)$ & \\
\hline & No change $(++)$ & $83(19.9)$ & \\
\hline \multirow[t]{4}{*}{ Self-care } & No change $(--)$ & $335(80.3)$ & $<0.001$ \\
\hline & Impairment $(-+)$ & $25(6.0)$ & \\
\hline & Improvement $(+-)$ & $46(11.0)$ & \\
\hline & No change $(++)$ & $11(2.6)$ & \\
\hline \multirow[t]{4}{*}{ Usual activities } & No change $(--)$ & $172(41.3)$ & $<0.001$ \\
\hline & Impairment $(-+)$ & 65 (15.6) & \\
\hline & Improvement (+ -) & $116(27.9)$ & \\
\hline & No change $(++)$ & $63(15.1)$ & \\
\hline \multirow[t]{4}{*}{ Pain/discomfort } & No change $(--)$ & $68(16.3)$ & $<0.001$ \\
\hline & Impairment $(-+)$ & 76 (18.2) & \\
\hline & Improvement (+ -) & $136(32.6)$ & \\
\hline & No change $(++)$ & 137 (32.9) & \\
\hline \multirow[t]{4}{*}{ Anxiety/Depression } & No change $(--)$ & $186(44.6)$ & $<0.001$ \\
\hline & Impairment $(-+)$ & $55(13.2)$ & \\
\hline & Improvement (+ -) & $93(22.3)$ & \\
\hline & No change $(++)$ & $83(19.9)$ & \\
\hline
\end{tabular}

- - no problem level to no problem level (no change); - + lower problem level to a higher problem level (impairment); +- higher problem level to a lower problem level (improvement); + + higher problem to higher problem (no change) 
Table 4 Multivariable linear regression analyses showing predictors of quality of life at 12-month follow-up using post EQ-5D-5L index value

\begin{tabular}{lll}
\hline Predictors & \multicolumn{2}{l}{ Complete cases analysis $(\boldsymbol{N}=417)$} \\
\cline { 2 - 3 } & $\beta(95 \% \mathrm{Cl})$ & $\boldsymbol{p}$-value \\
\hline Baseline EQ-5D-5L score & $0.60(0.52,0.67)$ & $<0.001$ \\
Number of chronic conditions & $0.02(-0.01,0.02)$ & 0.832 \\
Diagnosis of a respiratory disease & & \\
No $(n=298)$ & 1.00 (reference category) & \\
Yes $(n=119)$ & $-0.03(-0.06,-0.01)$ & 0.034 \\
\hline
\end{tabular}

B- unstandardized beta coefficient (slope)

out of $30(50 \%)$ patients had met the MCID criteria for HOOS at follow-up.

The Pearson's product-moment correlation coefficient correlation test between changes in EQ. 5D with HOOS and KOOS resulted in a weak but significant positive association of $r=0.395$ and $r=0.285$ respectively.

\section{Discussion}

To our knowledge, WellNet study is the first study to evaluate the changes in HRQoL among patients with one or more chronic conditions in Australian primary care settings based on the principles of PCMH model. Findings of this study are consistent with the growing body of evidence showing strong association between patients' HRQoL and several core elements of the PCMH such as involvement of a MDT [40, 41], continuity of care $[42,43]$, and shared decision making and patient-provider communication [22, 23]. Previous Australian studies by McCaffrey et al. [24] and others [44] have reported on health utilities and HRQoL on the general population norms using cross-sectional data.
However, studies reporting on the disease-specific, high risk sub-group population using GP data are relatively less, which is of interest, as primary care is the forefront of care delivery in Australia with at least $85 \%$ of Australians consulting a GP every year [3]. In view of this, the WellNet study is novel as it closely examines the outcome of integrating care delivery on HRQoL at two different time points whilst determining predictors of change using GP data.

In this study, the use of EuroQol EQ-5D-5L over other instruments owes to its simplicity in accruing several aspects of an individual's self-perceived health status in a relatively short duration through use of a short 5-item questionnaire [45]. Moreover, the EQ-5D-5L has also been reported as one of the sensitive instruments in terms of better discriminative power in effectively detecting changes in the HRQoL [46]. In addition, it is reported to have better known-group validity where subjective patient scores are shown to be in accordance with the objective investigator findings of changes in the HRQoL [47].

Findings of our study showed both statistical significance whilst also meeting the bare minimal threshold of clinical significance in EQ-5D index scores after adjusting for baseline covariates. However, considering that our sample is chronically ill with many patients having multiple diseases, MCID may not even be a significant indicator on population level. In this population, we would typically expect that many patients would have progressed in their disease, so even small change or no change in the EQ. 5D scale may be a positive outcome for the program. The effectiveness of PCMH model on improving patients' HRQoL is consistent with studies by Schuttner et al. [13] and Hynes et al. [14].

Of the five dimensions of EQ-5D, WellNet patients reported substantial improvement particularly on two domains of pain/discomfort and usual activities in terms of

Table 5 Adjusted mean differences in HOOS and KOOS assessment (short version) at baseline and follow-up

\begin{tabular}{|c|c|c|c|c|}
\hline Variables & Baseline Mean (SD) & $\begin{array}{l}\text { Follow-up } \\
\text { Mean (SD) }\end{array}$ & $\begin{array}{l}\text { Adjusted mean } \\
\text { difference } e^{\mathbf{a}} \\
(95 \% \mathrm{Cl})\end{array}$ & $\boldsymbol{P}$ value \\
\hline \multicolumn{5}{|l|}{ KOOS scales $(N=55)^{b}$} \\
\hline KOOS pain score & $65.0(21.7)$ & $76.2(22.0)$ & $10.6(3.1,18.2)$ & 0.05 \\
\hline KOOS function score & $62.5(24.8)$ & $69.8(25.7)$ & $6.5(-1.6,14.6)$ & 0.114 \\
\hline KOOS symptom score & $63.1(17.8)$ & $70.7(18.7)$ & $7.2(1.2,13.1)$ & 0.019 \\
\hline KOOS stiffness score & $61.8(27.9)$ & $68.2(26.1)$ & $7.0(-1.1,15.1)$ & 0.090 \\
\hline \multicolumn{5}{|l|}{ HOOS scales $(N=30)^{c}$} \\
\hline HOOS pain score & $65.0(23.1)$ & $77.5(25.1)$ & $11.6(3.2,20.0)$ & 0.008 \\
\hline HOOS function score & $71.7(17.8)$ & $81.2(20.4)$ & $8.6(1.1,16.1)$ & 0.026 \\
\hline HOOS symptom score & $67.6(16.6)$ & 78.5 (19.6) & $10.3(3.7,16.8)$ & 0.003 \\
\hline
\end{tabular}

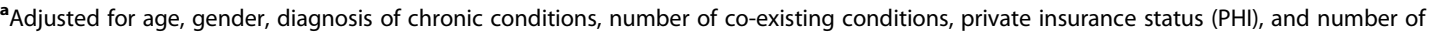
scheduled consultations

b 24 out of 55 (44\%) patients had adjusted mean differences $\geq$ MCID for KOOS at follow-up

${ }^{c} 15$ out of $30(50 \%)$ patients had adjusted mean differences $\geq$ MCID for HOOS at follow-up 
a 33 and $28 \%$ increase, respectively, in the 'no problem' level at follow-up. This could be attributed to the primary objective of the WellNet program in improving self-management behaviour among patients to effectively manage symptoms associated with their chronic conditions [27]. Improved self-management behaviours are strongly associated with improved HRQoL [48, 49].

Findings of the multivariable regression model show that higher baseline index value and positive diagnosis of respiratory disease were significantly associated with EQ-5D index at 12 months. Higher baseline EQ-5D index value as significant predictor of increased followup index scores is consistent with other study findings by Van Eck et al. [39]. This could be because patients who already reported better HRQoL at baseline benefitted through further patient education and selfmanagement from the WellNet care team. A positive history of respiratory disease was negatively associated with HRQoL at follow-up compared to those without prior respiratory disease. The poor HRQoL reported among patients with respiratory disease due to several reasons of duration and severity of the condition supplemented with or without harmful lifestyle behaviours is well documented [50, 51].

KOOS and HOOS assessments were recorded in parallel with EQ. 5D instrument in the WellNet study. Changes in the KOOS and HOOS scores were supplemented with the primary outcome of EQ. 5D changes. Besides statistical significance, the scores also met the MCID rendering them clinically relevant for changes in the patient management. The favourable changes in this study is consistent with findings of other studies of collaborative care [52, 53].

Our study has several strengths and limitations. This is the first study in Australia to evaluate the outcome of a PCMH model on HRQoL among patients in primary care setting. The study includes an effectively targeted sample with longitudinal measurements at two different time intervals enabling determining predictors of change in the HRQoL scores. This study also exhibited a good response rate of $68 \%$ which is high and satisfactory in this kind of survey [54]. This study also adds to the relatively less than adequate research conducted using GPdata. Although the aim of this study was to evaluate changes in HRQoL after the 12-month WellNet intervention, this study was not designed as an effectiveness study, but rather as a proof-of-concept study.

In regard to study limitations, although WellNet program comprises an effectively matched comparison group, the EuroQol EQ-5D-5L was recorded only among treatment group, thereby limiting to within-group analysis. The lack of control group means that the possibility of potential bias cannot be excluded, and we cannot be sure that improvement in $\mathrm{EQ}$. $5 \mathrm{D}$ scores may have occurred anyway without the enhanced PCMH intervention. However, that seems unlikely based on research conducted with use of control groups reporting similar outcomes [55, 56]. Additionally, some key socioeconomic variables such as annual income were unavailable due to privacy concerns, which may also have impacted prediction of the index scores over time. With exception of HOOS and KOOS surveys, we did not have other validated instruments to determine HRQoL in parallel with the EQ-5D-5L instrument, which could have further increased the reliability of the findings. Finally, consistent with other originally designed programs, reproducibility of findings is constrained by potential barriers in the form of uniqueness of data and by patient and provider-level determinants $[27,57]$.

\section{Conclusion}

Evaluating the HRQoL for patients with chronic illness enables understanding of patient's insights and perception on where care needs to be directed in relation to their condition. The integration of GPs and trained CDM coordinators proves critical for provision of individualised care for patients presenting with multiple chronic conditions. This study demonstrates outcome of integrating care delivery on HRQoL at two different time points whilst determining predictors of change using GP data. Besides statistical significance, patients also met the MCID rendering them clinically relevant for change in patient management. Future research should seek to evaluate the sustained effects and cost-benefits of the WellNet program.

\section{Abbreviations}

ANCOVA: Analysis of covariance; BMI: Body mass index; CC: Clinical coordinator; CDM: Chronic disease management; Cl: Confidence interval; CVD: Cardiovascular disease; EQ-5D-5L: EuroQol Five Dimensions Five Levels; FCS: Fully conditional specification; GP: General practitioner; HOS: Health Omnibus Survey; HOOS: Hip disability and osteoarthritis outcome scores; HRQoL: Health-related quality of life; KOOS: Knee injury and Osteoarthritis Outcome Scores; MCID: Minimal clinically important difference; MCMC: Markov Chain Monte Carlo; MDT: Multidisciplinary team; NSW: New South Wales; PCMH: Patient Centred Medical Home; PHI: Private health insurance; PROMS: Patient reported outcome measures; SCS: Sonic Clinical Services; SD: Standard Deviation; SPSS: Statistical Package for the Social Sciences

\section{Acknowledgements}

This paper uses unit record data from the WellNet Program in the Northern Sydney region. The WellNet Program was initiated and funded by the WellNet partners, SCS, Northern Sydney PHN, Bupa, HCF, NIB and Teacher's Health. We are especially thankful to Sonic Clinical Services for collecting and sharing the patient data, providing insights on the development and delivery of WellNet.

We are particularly grateful to the health care team from the participating primary care practices for their high-quality work in data collection. We wish to thank Munro Neville, Shima Ghassempour, Federico Girosi and Evan Atlantis for input and feedback provided for this study.

\section{Informed consent}

Informed consent was obtained from all individual participants included in the study. 


\section{Authors' contributions}

AJ was responsible for program administration and contributed to data acquisition; JRJ, WKT, and AJ contributed to methodology; Data curation and formal data analysis was performed by JRJ; JRJ was responsible for writing the original draft preparation; All authors have read and agreed to the submitted version of the manuscript.

\section{Funding}

JRJ's PhD scholarship was provided by Capital Markets Cooperative Research Centre (Now Rozetta Institute). The funders did not have any role in the design, methods, analysis, or preparation of this manuscript.

\section{Availability of data and materials}

WellNet data may not be available to the general public for security reasons.

\section{Ethics approval and consent to participate}

All procedures performed in studies involving human participants were in accordance with the ethical standards of the institutional and/or national research committee and with the 1964 Helsinki Declaration and its later amendments or comparable ethical standards. The study was reviewed by the Western Sydney University Human Research Ethics Committee (REDI Reference: H12215).

\section{Consent for publication}

Not applicable.

\section{Competing interests}

JRJ and KT have no competing interests. AJ is employed by SCS as the Operational Manager Integrated Care and is responsible for the implementation of WellNet. However, SCS and WellNet partners had no control or influence over the decision to submit the final manuscript for publication.

\section{Author details}

${ }^{1}$ Translational Health Research Institute, Western Sydney University, Campbelltown, Sydney, NSW 2560, Australia. ${ }^{2}$ Rozetta Institute (formerly Capital Markets Cooperative Research Centre), The Rocks, Sydney, NSW 2000, Australia. ${ }^{3}$ School of Business, Western Sydney University, Parramatta, NSW 2150, Australia. ${ }^{4}$ Sonic Clinical Services, The Rocks, Sydney, NSW 2000, Australia.

Received: 8 May 2020 Accepted: 17 August 2020

Published online: 24 August 2020

\section{References}

1. van Oostrom SH, Gijsen R, Stirbu I, Korevaar JC, Schellevis FG, Picavet HSJ, Hoeymans N. Time trends in prevalence of chronic diseases and multimorbidity not only due to aging: data from general practices and health surveys. PLoS One. 2016;11:e0160264.

2. Harrison C, Britt H, Miller G, Henderson J. Prevalence of chronic conditions in Australia. PLoS One. 2013;8:e67494.

3. Australian Institute of Health and Welfare. Australia's health 2018. AlHW. Canberra; 2018. https://www.aihw.gov.au/getmedia/fe037cf10cd0-4663-a8c0-67cd09b1f30c/aihw-aus-222.pdf.aspx?inline=true Accessed 21 Jan 2020.

4. Australian Bureau of Statistics. Causes of Death, Australia, 2017. https:/www. abs.gov.au/ausstats/abs@.nsf/Lookup/by\%20Subject/3303.0 2017 Main\%2 OFeatures Australia's\%20leading\%20causes\%20of\%20death,\%202017 2 Accessed 23 Jan 2020

5. Garin N, Koyanagi A, Chatterii S, Tyrovolas S, Olaya B, Leonardi M, Lara E, Koskinen S, Tobiasz-Adamczyk B, Ayuso-Mateos JL. Global multimorbidity patterns: a cross-sectional, population-based, multi-country study. J Gerontol A-Biol. 2015:71:205-14.

6. Hay SI, Abajobir AA, Abate KH, Abbafati C, Abbas KM, Abd-Allah F, Abdulkader RS, Abdulle AM, Abebo TA, Abera SF. Global, regional, and national disability-adjusted life-years (DALYs) for 333 diseases and injuries and healthy life expectancy (HALE) for 195 countries and territories, 19902016: a systematic analysis for the global burden of disease study 2016. Lancet. 2017;390:1260-344.

7. Gallacher Kl, McQueenie R, Nicholl B, Jani BD, Lee D, Mair FS, Risk factors and mortality associated with multimorbidity in people with stroke or transient ischaemic attack: a study of 8,751 UK biobank participants. JOC. 2018;8:1-8.

8. Vyas A, Pan X, Sambamoorthi U. Chronic condition clusters and polypharmacy among adults. Intern J Family Med. 2012;193168.

9. Marengoni A, Angleman S, Melis R, Mangialasche F, Karp A, Garmen A, Meinow B, Fratiglioni L. Aging with multimorbidity: a systematic review of the literature. Ageing Res Rev. 2011;10:430-9.

10. Fortin M, Lapointe L, Hudon C, Vanasse A, Ntetu AL, Maltais D. Multimorbidity and quality of life in primary care: a systematic review. Health Qual Life Outcomes. 2004;2:51.

11. Barnett K, Mercer SW, Norbury M, Watt G, Wyke S, Guthrie B. Epidemiology of multimorbidity and implications for health care, research, and medical education: a cross-sectional study. Lancet. 2012;380:37-43.

12. Salisbury C, Johnson L, Purdy S, Valderas JM, Montgomery AA. Epidemiology and impact of multimorbidity in primary care: a retrospective cohort study. Br J Gen Pract. 2011;61:e12-21.

13. Schuttner L, Reddy A, Rosland A-M, Nelson K, Wong ES. Association of the Implementation of the patient-centered medical home with quality of life in patients with multimorbidity. J Gen Intern Med. 2020;35:119-25.

14. Hynes DM, Fischer M, Fitzgibbon M, Porter AC, Berbaum M, Schiffer L, Chukwudozie IB, Nguyen H, Arruda J. Integrating a medical home in an outpatient dialysis setting: effects on health-related quality of life. J Gen Intern Med. 2019:34:2130-40.

15. Bowling A, Banister D, Sutton S, Evans O, Windsor J. A multidimensional model of the quality of life in older age. Aging Ment Health. 2002;6:355-71.

16. Asadi-Lari M, Tamburini M, Gray D. Patients' needs, satisfaction, and health related quality of life: towards a comprehensive model. Health Qual Life Outcomes. 2004;2:32.

17. Guyatt $\mathrm{GH}$, Feeny $\mathrm{DH}$, Patrick DL. Measuring health-related quality of life. Ann Intern Med. 1993:118:622-9.

18. Karimi M, Brazier J. Health, health-related quality of life, and quality of life: what is the difference? Pharmacoeconomics. 2016:34:645-9.

19. Higginson IJ, Carr AJ. Using quality of life measures in the clinical setting. BMJ. 2001:322:1297-300.

20. Greenhalgh J, Gooding K, Gibbons E, Dalkin S, Wright J, Valderas J, Black N. How do patient reported outcome measures (PROMs) support clinician-patient communication and patient care? A realist synthesis. JPRO. 2018:2:42.

21. Jonkman NH, Schuurmans MJ, Groenwold RH, Hoes AW, Trappenburg JC. Identifying components of self-management interventions that improve health-related quality of life in chronically ill patients: systematic review and meta-regression analysis. Patient Educ Couns. 2016;99:1087-98.

22. J-W L, M-s P. The relationship between communication and health-related quality of life in survivorship care for Chinese-American and KoreanAmerican breast cancer survivors. Support Care Cancer. 2013;21:1157-66.

23. Detmar SB, Muller MJ, Schornagel JH, Wever LD, Aaronson NK. Healthrelated quality-of-life assessments and patient-physician communication: a randomized controlled trial. JAMA. 2002;288:3027-34.

24. McCaffrey N, Kaambwa B, Currow DC, Ratcliffe J. Health-related quality of life measured using the EQ-5D-5L: south Australian population norms. Health Qual Life Outcomes. 2016;14:133.

25. Up Study Collaborators. Cohort profile: the 45 and up study. Int J Epidemiol. 2007;37:941-7.

26. Atlantis E, Goldney RD, Eckert KA, Taylor AW, Phillips P. Trends in healthrelated quality of life and health service use associated with comorbid diabetes and major depression in South Australia, 1998-2008. Soc Psychiatry Psychiatr Epidemiol. 2012;47:871-7.

27. John JR, Jones A, Neville AM, Ghassempour S, Girosi F, Tannous WK. Cohort profile: effectiveness of a 12-month patient-Centred medical home model versus standard care for chronic disease management among primary care patients in Sydney, Australia. Int J Environ Res Public Health. 2020;17:2164.

28. Sedgwick P. Convenience sampling. BMJ. 2013;347:f6304.

29. Devlin NJ, Shah KK, Feng Y, Mulhern B, van Hout B. Valuing healthrelated quality of life: an EQ-5 D-5 L value set for England. Health Econ. 2018;27:7-22.

30. Oppe M, Devlin NJ, van Hout B, Krabbe PF, de Charro F. A program of methodological research to arrive at the new international EQ-5D-5L valuation protocol. Value Health. 2014;17:445-53.

31. Barrett B, Brown D, Mundt M, Brown R. Sufficiently important difference: expanding the framework of clinical significance. Med Decis Mak. 2005: 25:250-61. 
32. Coretti S, Ruggeri M, McNamee P. The minimum clinically important difference for EQ-5D index: a critical review. Expert Rev Pharm Out. 2014;14:221-33.

33. Lyman S, Lee Y-Y, Franklin PD, Li W, Cross MB, Padgett DE. Validation of the KOOS, JR: a short-form knee arthroplasty outcomes survey. Clin Orthop Relat Res. 2016:474:1461-71.

34. Lyman S, Lee Y-Y, Franklin PD, Li W, Mayman DJ, Padgett DE. Validation of the HOOS, JR: a short-form hip replacement survey. Clin Orthop Relat Res. 2016;474:1472-82.

35. Free online Oswestry Disability Index (ODI) score calculator. OrthoToolKit. http://orthotoolkit.com/oswestry/ Accessed: Jan 3, 2020.

36. Nilsdotter A, Bremander A. Measures of hip function and symptoms: Harris hip score (HHS), hip disability and osteoarthritis outcome score (HOOS), Oxford hip score (OHS), Lequesne index of severity for osteoarthritis of the hip (LISOH), and American Academy of orthopedic surgeons (AAOS) hip and knee questionnaire. Arthritis Care Res. 2011;63(S11):S200-7.

37. Roos EM, Lohmander LS. The knee injury and osteoarthritis outcome score (KOOS): from joint injury to osteoarthritis. Health Qual Life Outcomes. 2003;1(1):1-8.

38. Bland JM, Altman DG. Regression towards the mean. BMJ. 1994;308:1499.

39. van Eck JM, van Hemel NM, van den Bos A, Taks W, Grobbee DE, Moons KG. Predictors of improved quality of life 1 year after pacemaker implantation. Am Heart J. 2008;156:491-7.

40. Hogg W, Lemelin J, Dahrouge S, Liddy C, Armstrong CD, Legault F, Dalziel B, Zhang W. Randomized controlled trial of anticipatory and preventive multidisciplinary team care: for complex patients in a community-based primary care setting. Can Fam Physician. 2009;55:e76-85.

41. Raz DJ, Sun V, Kim JY, Williams AC, Koczywas M, Cristea M, Reckamp K, Hayter J, Tiep B, Ferrell B. Long-term effect of an interdisciplinary supportive care intervention for lung cancer survivors after surgical procedures. Ann Thorac Cardiovasc Surg. 2016;101:495-503.

42. Nelson K, Sylling PW, Taylor L, Rose D, Mori A, Fihn SD. Clinical quality and the patient-centered medical home. JAMA Intern Med. 2017;177:1042-4.

43. Reddy A, Pollack CE, Asch DA, Canamucio A, Werner RM. The effect of primary care provider turnover on patient experience of care and ambulatory quality of care. JAMA Intern Med. 2015;175:1157-62.

44. Banham D, Hawthorne G, Goldney R, Ratcliffe J. Health-related quality of life (HRQoL) changes in South Australia: comparison of burden of disease morbidity and survey-based health utility estimates. Health Qual Life Outcomes. 2014;12:113.

45. Feng Y, Devlin N, Herdman M. Assessing the health of the general population in England: how do the three-and five-level versions of EQ-5D compare? Health Qual Life Outcomes. 2015;13:171.

46. Alvarez JA, Rezende K, Marocho SMS, Alves FB, Celiberti P, Ciamponi AL. Dental fluorosis: exposure, prevention and management. J Clin Exp Dent. 2009;1:14-8.

47. Janssen M, Pickard AS, Golicki D, Gudex C, Niewada M, Scalone L, Swinburn $P$, Busschbach J. Measurement properties of the EQ-5D-5L compared to the EQ-5D-3L across eight patient groups: a multi-country study. Qual Life Res. 2013;22:1717-27.

48. Tickle-Degnen L, Ellis T, Saint-Hilaire MH, Thomas CA, Wagenaar RC. Selfmanagement rehabilitation and health-related quality of life in Parkinson's disease: a randomized controlled trial. Mov Disord. 2010;25:194-204.

49. Joekes K, Van Elderen T, Schreurs K. Self-efficacy and overprotection are related to quality of life, psychological well-being and self-management in cardiac patients. J Health Psychol. 2007;12:4-16.

50. Zamzam MA, Azab NY, El Wahsh RA, Ragab AZ, Allam EM. Quality of life in COPD patients. Egypt J Chest Dis Tuberc. 2012;61:281-9.

51. Ahmed MS, Neyaz A, Aslami AN. Health-related quality of life of chronic obstructive pulmonary disease patients: results from a community based cross-sectional study in Aligarh, Uttar Pradesh, India. Lung India. 2016;33:148

52. Fernandes $L$, Roos EM, Overgaard S, Villadsen A, Søgaard R. Supervised neuromuscular exercise prior to hip and knee replacement: 12-month clinical effect and cost-utility analysis alongside a randomised controlled trial. BMC Musculoskelet Disord. 2017;18:5

53. Voorn VM, Vermeulen HM, Nelissen RG, Kloppenburg M, Huizinga TW, Leijerzapf NA, Kroon HM, Vlieland TPV, van der Linden HM. An innovative care model coordinated by a physical therapist and nurse practitioner for osteoarthritis of the hip and knee in specialist care: a prospective study. Rheumatol Int. 2013;33:1821-8.
54. Fincham JE. Response rates and responsiveness for surveys, standards, and the journal. Am J Pharm Educ. 2008;72(2):43.

55. Casañas R, Catalán R, Del Val JL, Real J, Valero S, Casas M. Effectiveness of a psycho-educational group program for major depression in primary care: a randomized controlled trial. BMC Psychiatry. 2012;12:230.

56. Kessler D, Lewis G, Kaur S, Wiles N, King M, Weich S, Sharp DJ, Araya R, Hollinghurst S, Peters TJ. Therapist-delivered internet psychotherapy for depression in primary care: a randomised controlled trial. Lancet. 2009; 374:628-34.

57. John JR, Tannous WK, Jones A. Effectiveness of a patient-centered medical home model of primary care versus standard care on blood pressure outcomes among hypertensive patients. Hypertens Res. 2020;1:1-1.

\section{Publisher's Note}

Springer Nature remains neutral with regard to jurisdictional claims in published maps and institutional affiliations.
Ready to submit your research? Choose BMC and benefit from:

- fast, convenient online submission

- thorough peer review by experienced researchers in your field

- rapid publication on acceptance

- support for research data, including large and complex data types

- gold Open Access which fosters wider collaboration and increased citations

- maximum visibility for your research: over $100 \mathrm{M}$ website views per year

At BMC, research is always in progress.

Learn more biomedcentral.com/submissions 